\title{
Charlie Gard: in defence of the law
}

\author{
Eliana Close, Lindy Willmott, Benjamin P White
}

Australian Centre for Health Law Research, Queensland University of Technology, Brisbane, Queensland, Australia

\section{Correspondence to}

Eliana Close, Australian Centre for Health Law Research, Queensland University of Technology, Brisbane, QLD 4000, Australia:

eliana.close@qut.edu.au

Received 20 December 2017

Revised 14 February 2018

Accepted 19 February 2018

Published Online First

3 May 2018

\section{SLinked}

- http://dx.doi.org/10.1136/ medethics-2017-104718

Check for updates

To cite: Close E, Willmott L, White BP.J Med Ethics 2018:44:476-480.

\section{ABSTRACT}

Much of the commentary in the wake of the Charlie Gard litigation was aimed at apparent shortcomings of the law. These include concerns about the perceived inability of the law to consider resourcing issues, the vagueness of the best interests test and the delays and costs of having disputes about potentially life-sustaining medical treatment resolved by the courts. These concerns are perennial ones that arise in response to difficult cases. Despite their persistence, we argue that many of these criticisms are unfounded. The first part of this paper sets out the basic legal framework that operates when parents seek potentially life-sustaining treatment that doctors believe is against a child's best interests, and describes the criticisms of that framework. The second part of the paper suggests an alternative approach that would give decision-making power to parents, and remove doctors' ability to unilaterally withhold or withdraw life-sustaining treatment that they regard is futile. This proposal is grounded in several values that we argue should guide these regulatory choices. We also contend that the best interests test is justifiable and since the courts show no sign of departing from it, the focus should be on how to better elucidate the underlying values driving decisions. We discuss the advantages of our proposed approach and how it would address some of the criticisms aimed at the law. Finally, we defend the current role that the judiciary plays, as an independent state-sanctioned process with a precedentsetting function.

\section{INTRODUCTION}

The Charlie Gard case has generated extensive philosophical, social, economic and legal commentary on whether (and, if so, at what stage) experimental treatment should have been provided to Charlie, and how events could have unfolded in a better, or at least less awful, manner. We seek to contribute to the debate by providing a legal perspective. Such a perspective is justifiable as many of the criticisms in this debate have been directed towards the perceived failings of the law: its inability to identify 'best interests'; its failure to engage with issues of resourcing; and concerns around delay and expense which are commonly levelled at the law as a means of resolving disputes.

We write (largely) in defence of the current legal framework. We argue that the criterion of best interests to resolve intractable disputes around withholding and withdrawing potentially life-sustaining treatment is sound. We also defend courts (or tribunals) as the final arbiter of disputes because they are independent from doctors and hospitals. However, we do believe there is room for improvement in the regulatory context within which decisions about treatment are made, and that improvement should be driven by the values that currently underpin many aspects of our legal system.

The goal of this article is twofold. First, we suggest how the regulatory framework can be adjusted to better reflect the relevant core values that we identify. This adjustment includes providing parents with greater power around treatment that they want their child to receive while, at the same time, building in structural limits to that power. The second goal is to defend the role of courts (or tribunals) when disputes between doctors and parents cannot otherwise be resolved.

We begin by briefly outlining the law that currently governs treatment disputes, and the major criticisms that have been levelled at the law in the wake of the Gard case.

\section{LEGAL FRAMEWORK FOR DISPUTES ABOUT LIFE- SUSTAINING TREATMENT}

The legal position in the UK on withholding or withdrawing life-sustaining treatment from critically ill infants like Charlie Gard is reasonably straightforward in principle, if not in application. The courts have described the process as a 'joint decision"1 between doctors and those who have parental responsibility. This shared decision-making process is subject to two qualifications. First, parents have a duty to make decisions according to the child's best interests, not according to their own. ${ }^{12}$ Second, while doctors must involve parents in decision-making, ${ }^{3}$ they have no obligation to provide treatment when responsible medical opinion is of the view that it is against the patient's best interests or is 'futile'. ${ }^{145}$ In other words, parents cannot compel doctors to provide treatment that doctors do not think is medically indicated. ${ }^{14}$

The vast majority of disputes about limiting life-sustaining treatment are resolved through a consensus-building process, without going to court. ${ }^{6}$ When a dispute becomes intractable, however, either the parents or the hospital can apply to the court for a determination of whether it is in the child's best interests to provide the requested treatment..$^{5}$ This is an objective inquiry into a broad range of factors and includes 'medical, emotional, and all other welfare issues'. ${ }^{8}$ There is a strong presumption in favour of providing continued treatment. ${ }^{5}$ The court must balance conflicting considerations to ultimately determine the child's best interests, which will vary case by case. ${ }^{7}$ From a practical perspective, while there is no legal requirement to bring the matter to court, ${ }^{4}$ when a dispute becomes entrenched the court's input is usually sought as a matter of good practice. $^{9}$ 
Most disputes about potentially life-sustaining treatment that reach the courts, like the Charlie Gard case, are best interests applications. However, such conflict can also raise concerns about the efficient use of scarce health resources. Another legal avenue exists when treatment is withheld because it is not cost-effective: an action for judicial review. In the well-known Child B case, ${ }^{10}$ the father of 10 -year-old Jaymee Bowen brought such an action in response to the health authority's refusal to fund expensive experimental cancer treatment. The case considered both whether the treatment was 'clinically appropriate' and whether it was an 'effective use of the Authority's limited resources'. The Court of Appeal refused to compel the health authority to provide the treatment as it was not for courts to get involved in these 'difficult and agonising' resource allocation decisions, which require judgment about how to prioritise a limited budget across all patients. The courts usually refuse to intervene in resource allocation decisions, because they recognise they are poorly situated to make these prioritisation decisions in the context of a single case. While they will invariably not adjudicate on the substance of resource allocation decisions, they will however evaluate the decision-making process. ${ }^{11}$ But a threshold issue is that for the courts to consider resources in a decision about potentially life-sustaining treatment, there must be an explicit rationing decision, or at least evidence to suggest that one was made, which was not present in the Gard case. Charlie's family had raised the funds to pay for the experimental treatment in the USA, and the Great Ormond Street Hospital clinicians had based their treatment refusal solely on Charlie's best interests.

\section{CRITICISMS OF THE CURRENT LEGAL APPROACH}

The criticisms of the Gard case centred on three areas: the lack of a mechanism to address concerns about resources; criticism of the best interests standard; and problems with court involvement.

The first criticism is that the law does not sufficiently engage with issues of limited healthcare resources. One rationale for denying life-sustaining treatment is that the expected benefit is too low (or too uncertain) to justify the cost to the public health system. In cases like Gard's, when there is uncertainty about whether a treatment is in a child's best interests, this distributive justice argument can provide a clearer ethical rationale for treatment refusal. Low cost-effectiveness is a reason to deny a treatment even if it is established that it is in the patient's best interests to try it. ${ }^{12}$ Wilkinson and Savulescu contend that one barrier to giving effect to this rationale is that 'there is no legal mechanism for courts to adjudicate on the issue of resources where there is a dispute. ${ }^{12}$ This criticism raises two related points about the law. First, it is not strictly true to assert that there is no legal mechanism to adjudicate on the issue of resources (a point that Wilkinson and Savulescu appear to recognise). Courts can address resource-based treatment denials in an action for judicial review, although only when a rationing decision is made explicitly, as it was in the Child $B$ case. ${ }^{10}$ This requires policies to support resource-based decisions about intensive care however, which Wilkinson and Savulescu ${ }^{12}$ observe are lacking. The second point is that in an action that involves only a best interests application, like the Charlie Gard case, it is true that the court cannot consider cost-effectiveness, even if it is a valid ethical concern. ${ }^{13}$ Charlie Gard was occupying an intensive care unit bed that could have provided more benefit to another patient, and Wilkinson and Savulescu argue that a lesser harm overall may have been to allow him to access the experimental treatment overseas months earlier, to free up these vital resources for others. ${ }^{12}$ Yet, this was not relevant to the court's deliberations, which were focused solely on Charlie's best interests.

A second criticism of the law in response to Gard was that the best interests standard itself is problematic. At the heart of this criticism is that the best interests test is unclear, ${ }^{14}{ }^{15}$ is inconsistently applied and varies based on the values of the assessor. ${ }^{13} 14$ This inability to provide a precise and objective meaning to best interests has led to several proposed alternatives, ${ }^{16}$ including calls to permit parents to access any treatment that does not harm the child. ${ }^{17}$ The parents' counsel in Gard (unsuccessfully) employed a version of this argument on appeal, contending that when a 'viable alternative treatment option' is desired by the parents, the court should accede to it unless it would cause the child 'significant harm'. 18

A third criticism raised in response to Gard is that the courts are ill-suited to resolve these disputes. Some view the law as an intrusion into what are rightly clinical matters. ${ }^{19}$ Others accept the validity of the courts as decision-maker but complain that they add unnecessary delay and cost to an already difficult process. ${ }^{122021}$ For example, Wilkinson and Savulescu argued that the court process in Gard, with its 'lengthy process of adjudication and appealing', resulted in the 'worst of possible outcomes', as no party had a satisfactory result. ${ }^{12}$ Charlie Gard received months of intensive care support that doctors believed was against his interests, and the parents' bid for further treatment was unsuccessful. Wilkinson and Savulescu suggest an 'independent ethics committee', ${ }^{12}$ with ethical and medical expertise, as a potential solution.

\section{AN ALTERNATIVE APPROACH GROUNDED IN KEY VALUES}

Despite these criticisms of the law, we argue that the current system is defensible. Our position is grounded in a set of values that we have elsewhere proposed should guide regulation in this field. ${ }^{22} 23$ These values, set out in box 1 , are drawn from existing commitments made through legislation, the common law, conventions and treaties.

To an extent, these values are promoted in the current legal framework in countries like the UK, Australia, Canada and New Zealand. We believe that a small but significant change to the legal framework could better promote these values and, at the same time, address some of the concerns levelled at the law in cases such as Charlie Gard.

\section{An alternative approach: shift decision-making power to the parents}

We have elsewhere proposed an alternative approach to decision-making where there is a dispute about best interests. ${ }^{22} 23$ Our suggestion is that doctors should not have the power (which they possess under the current law) to unilaterally withdraw or withhold treatment that they regard to be futile. Parents have authority to consent to medical treatment, and we think this should extend to potentially life-sustaining treatment even if doctors regard the treatment as 'futile' or 'against best interests'. In other words, they should be able to insist on that treatment being given to the infant. We suggest two limitations to this proposition. The first is if there is a physiological impossibility that the treatment could achieve the desired goal. This is when there is no basis for the treatment, theoretical or otherwise. For example, cardiopulmonary resuscitation for a body in rigor mortis or antibiotics for a virus. The second limitation is if the treatment is denied in accordance with a valid resource allocation policy. In these cases, the treating team could legitimately refuse 
Box 1 Key values to guide regulation of disputes about potentially life-sustaining treatment

Values centred on the individual patient

- Life (the importance of life is central to many civil and criminal legal protections).

- Autonomy (the value which underpins both medical ethics and legal requirements around consent).

- Equality (to ensure that discrimination does not occur based on perceptions about quality of life for those with a disability).

\section{Values promoting the integrity of the regulatory system}

- Rule of law (requiring the law to be readily known, available, certain and clear).

- Procedural fairness (to ensure that decisions are made and policies are developed in a transparent manner that can be challenged).

- Access to justice (to facilitate challenge of decisions that affect the individual or their loved one).

Values recognising viewpoints external to the patient (societal, medical, parental)

- Distributive justice (allocation of resources for maximum societal benefit).

- Conscience (both of a health professional being asked to provide treatment and of a parent requesting that treatment).

- Humility (understanding that there may be more than one legitimate perspective regarding treatment).

the treatment requested and the onus would then move to the parents to challenge the decision. Absent those two exceptions, doctors would be required to provide the requested treatment or challenge the parents' decision in court. Grounds for challenge could be disagreement about the potential for benefit or that the treatment would harm the child. This position recognises that most decisions about the continuation of life-sustaining treatment are value-laden and subjective. Accordingly, subject to these two exceptions, the values of parents should prevail unless the court orders otherwise.

We hypothesise that this model would have at least two consequences, which we discuss in more detail elsewhere. ${ }^{22}$ The first is that it would help balance the relationship between parents and hospital. In disputes about life-sustaining treatment generally power is in favour of the health system as parents will often lack resources, ability and capacity to bring litigation. By reversing the decision-making starting point, the small number of cases with intractable disputes must be escalated to court by the hospital. This is a subtle change, as it legally enshrines what often occurs in practice and what the Royal College of Paediatrics and Child Health (RCPCH) guidelines recommend in an intractable dispute. ${ }^{9}$ Nevertheless, it recognises the legitimacy of parents to make a critical and value-laden decision about medical treatment for their child.

The second consequence is that this would encourage more transparency in the underlying rationale(s) for treatment limitation. When parents request a treatment that doctors believe will not accomplish the physiological goal, doctors will need to articulate that. When there is a resource allocation policy that precludes treatment, for example, a triage or organ allocation policy, doctors would need to identify the policy and the criteria which prioritise other patients. Parents could then dispute the policy itself, or its application, in court. Again, given the existing ethical principles in the RCPCH guidelines, ${ }^{9}$ this proposal might be a subtle shift as these discussions may be already occurring. However, the resource-based exception would encourage development of more explicit resource-based policies, which could then be legally challenged.

\section{Retain best interests but improve its application}

Our second suggestion for how to refine the current legal approach relates to how a court should resolve a non-treatment dispute if a doctor challenges a parental decision. Despite the criticisms above, we believe that best interests is an appropriate test. There is not sufficient space to fully engage with the extensive debate about best interests here, but we endorse it for reasons articulated by Pope. ${ }^{24}$ It is a long-standing, well-known criterion that underpins a variety of judicial determinations about children (including in a number of non-medical contexts). While best interests encompasses consideration of harm, the harm principle lacks the broad range of important considerations that are captured in the best interests standard. ${ }^{24}$ Moreover, as the Gard litigation illustrated, the courts are unwilling to depart from the best interests test. Therefore, the focus should instead be on improving how the test is applied to provide clarity about the values underpinning decisions. The courts need to more clearly articulate the factors that inform its decision, and how those factors are balanced to arrive at its decision. A transparent and rigorous application of the 'balance sheet approach', used by some English courts, ${ }^{25}$ is one way to achieve this. Courts should also be less deferential to doctors' opinions and recognise that assessments about best interests are informed by a range of values. For example, parents may value keeping alive a newborn who has severe cognitive impairments and will always require life-sustaining treatment for survival, while the treating team may regard that treatment as burdensome and not in the infant's best interests. While it is appropriate, we would argue, for the court to determine such disputes, it should be clear that the disputes are value-laden.

\section{Advantages to our proposed approach}

There are advantages to our proposed approach. By nominating the parents as the decision-makers, many of the values articulated in box 1 are promoted. The value of life is promoted as treatment cannot be unilaterally withheld or withdrawn when the parents wish treatment to continue, and autonomy is promoted by allowing the decision to be made by the infant's substitute decision-maker. Equality is promoted as it prevents doctors from making unilateral decisions based on their assessments of the value of life. The process we suggest promotes access to justice as the obligation to bring an action is on those who can better afford to do so, the doctors and health authorities (rather than the parents), and recognises that there are non-clinical components to decision-making (humility).

We anticipate this approach could also lead to cultural change. The resource problem highlighted in response to Gard is not a legal one; rather it is that doctors and hospitals rarely couch decisions to limit life-sustaining treatments in terms of cost-effectiveness. Promoting the value of distributive justice requires trade-offs between patients, value judgments about where scarce resources should be diverted, and decisions about when resources should take precedence over a patient's best interests, all matters better dealt with by policies rather than case-by-case decisions of the courts. On our approach, knowledge that parents are the decision-makers may force the hand of doctors and health authorities to develop resource allocation policies that would 
limit treatment when the chance of success is very low. These policies must be developed in a reasoned, coherent, ethical and just way so that the value of distributive justice can be promoted in a procedurally-fair manner. The development of such policies would also result in more transparent decision-making (an aspect of procedural fairness). More treatment limitation decisions could be based on rationing, and there would be less need to cloak rationing decisions as best interests ones.

Finally, if courts were prepared to more transparently articulate how they arrive at a best interests assessment, the rule of law would be promoted by providing clarity and certainty regarding legal rights and interests.

\section{A DEFENCE OF COURT INVOLVEMENT}

We have argued that the current legal position is defensible, but requires refinements to better align with key values. We now turn to the third area of criticism, the role of the courts in resolving intractable disputes. Whether courts should have a role is not a hypothetical question. In the USA, Texas through its Advance Directives Act has effectively precluded substantive (not procedural) court involvement. ${ }^{26} 27$ Our position, however, is that a judicial process best advances the values we endorse above (box 1), although imperfectly.

As a starting point, it is important to note that some of the discontent about court involvement might be based on disagreement about what values a decision-making process should reflect. For example, Wilkinson and Savulescu have called for a 'fair, expedient' process. ${ }^{12}{ }^{15}$ But the factors that might make a decision fair-such as due process, opportunities for deep reflection, collection of all relevant information and an avenue to contest a decision-can result in a decision not being expedient. Similarly, an expedient process, such as unilateral and final decision-making by a clinician, would not be fair. Similar issues arise in relation to appeals (a subject of criticism by some). ${ }^{12}$ Appeal mechanisms are an important check on the power of the state and guard against poor or idiosyncratic decision-making. But appeals take time-especially in cases like this that were appealed to three higher-level courts-even when individual courts can hear and decide on cases relatively quickly. ${ }^{i}$ Compromises might be needed, reflecting that values we want to see in decision-making conflict.

Critics of judicial decision-making also need to understand that these cases have both private and public functions. There is clear resolution of a private disagreement occurring but these decisions also create public statements, and sometimes binding precedent, so there is an important public aspect as well. ${ }^{21} 2829$ Any critic of the courts' role should take account of that too. Private parties may have to endure a less than optimal process if that promotes better future decision-making (benefitting parties presently unknown at the time but including future patients, families and clinicians).

This is not to completely dismiss concerns that have been raised about the Gard litigation. Existing practices are problematic, especially in relation to cost, delay and adversarialism. ${ }^{12}$ Some of this may be impossible to avoid. Compelling clinicians to treat against their conscience or stopping treatment against parents' views will involve conflict and ill feelings, even with the most sensitive decision-making process. And indeed, this could

${ }^{\mathrm{i}}$ In the Gard litigation, for example, evidence in the first High Court case was heard on 3, 5, 7 April 2017, and the decision was issued just 4 days later, on 11 April 2017: Great Ormond Street Hospital v Yates and Ors [2017] EWHC 972. point to the utility of the courts as an independent State-endorsed decision-maker.

While some adversarialism is unavoidable, there may be ways to address concerns about cost and delay. One approach used in Australia and elsewhere including Ontario, Canada, is to empower quasi-judicial multi-member tribunals. ${ }^{30}$ These tribunals are often multidisciplinary and provide scope to convene a panel with both clinical and ethical expertise. England has a tribunal system in operation but it does not have jurisdiction in this area. Tribunals may better achieve the fair and expedient forum called for by Wilkinson and Savulescu. ${ }^{12} 15$ They are generally not bound by rules of evidence and can operate more flexibly (and quickly) than courts. Tribunals are also generally more inquisitorial rather than adversarial which means they can call their own evidence and are not constrained by the parties in the issues they can consider.

There are similarities between tribunals and the independent ethics committee' proposed by Wilkinson and Savulescu. ${ }^{12}$ The suggestion about obtaining appropriate ethical and medical evidence is possible in both models and is something which tribunals in other countries have done in making decisions about life-sustaining treatment. ${ }^{31} 32$ However in our view, tribunals have some significant advantages over the ethics committee model. One is that tribunals represent the State and their decisions are generally enforceable at law. Another is they often have a duty to give publicly-available reasons. These features promote transparency and contribute to the certainty of future decision-making (although tribunal decisions are not binding precedent). ${ }^{21}$ We also note that the Texas approach, which uses an ethics committee as decision-maker, has been widely regarded as lacking fairness ${ }^{2627}$ although we accept that it would be possible to address some of those concerns through better design.

This is not to suggest that tribunals do not have drawbacks too. Inquisitorial processes can lead to unnecessarily broad investigations, lack the precedent-setting function of courts and can have problems with delay depending on their appeals processes. ${ }^{33} \mathrm{~A}$ better approach for these disputes might be to simply streamline court processes, for example, by allowing judges greater latitude to narrow the issues involved and determine how evidence is received. While there are many possible reforms, addressing these concerns about litigation are perennial challenges.

No process designed to resolve intractable disputes-by definition, challenging problems-will be perfect. Compromises must be made and will depend on what priority one gives to each of the values we articulate (or indeed, other values). Our point though is that an external forum, such as a court or a tribunal, is needed and critics of its role should take account of these tradeoffs when evaluating the chosen process. Good decision-making that meets the values outlined in this paper may take time, and perhaps that is justifiable.

\section{CONCLUSION}

The law on withholding and withdrawing life-sustaining treatment from infants like Charlie Gard is sound, even though difficult cases might prompt criticisms to the contrary. Best interests is an appropriate test, despite the need for more clarity in its application, and an independent judicial or quasi-judicial process for resolving intractable disputes is warranted, given the gravity of the issues involved. It is also justifiable that resource tradeoffs are left to administrative decision-makers, rather than the courts. Although the current legal approach is adequate, it could be improved by removing doctors' present ability to unilaterally withhold or withdraw treatment that they regard is futile. 
Shifting power to parents in this way would better promote the range of values that underpin the legal system. This approach could also prompt the development of more policies to support doctors in making rationing decisions, providing an avenue for necessary discussions about resources and transparent challenge and consideration by the courts.

Contributors All authors discussed the content of the article. EC produced an outline. LW and BPW refined the outline. EC was responsible for the manuscript preparation and LW and BPW contributed to the writing. All authors edited the manuscript and approved the final version.

Funding EC was supported by an Australian Government Research Training Program Scholarship and a National Health and Medical Research Council Centre of Research Excellence in End-of-Life Care Top-Up Scholarship.

Competing interests LW is an associate editor of the Journal of Medical Ethics. Provenance and peer review Not commissioned; externally peer reviewed.

(c) Article author(s) (or their employer(s) unless otherwise stated in the text of the article) 2018. All rights reserved. No commercial use is permitted unless otherwise expressly granted.

\section{REFERENCES}

1 Re J (a minor) (wardship: medical treatment) [1990] 3 All ER 930 (CA).

2 Children Act 1989

3 Glass v the United Kingdom (App no 61827/00) [2003] ECHR 719.

4 R (Burke) v General Medical Council \& Ors [2005] EWCA 1003.

5 Re A (a child) [2016] EWCA Civ 759.

6 Brierley J, Linthicum J, Petros A. Should religious beliefs be allowed to stonewall a secular approach to withdrawing and withholding treatment in children? J Med Ethics 2013;39:573-7.

$7 \operatorname{Re} A$ (medical treatment: male sterilisation) [2000] 1 FLR 549 (CA).

8 Wyatt v Portsmouth NHS Trust [2005] EWHC 117 (Fam).

9 Larcher V, Craig F, Bhogal K, et al. Making decisions to limit treatment in life-limiting and life-threatening conditions in children: a framework for practice. Arch Dis Child 2015;100(Suppl 2):s1-s23.

10 R v Cambridge Health Authority, ex parte B [1995] EWCA 49 (Civ).

11 Newdick C. Who Should We Treat? Rights and Rationing in the NHS. 2nd ed. New York: Oxford University Press, 2005:93-126.

12 Wilkinson D, Savulescu J. Hard lessons: learning from the Charlie Gard case. J Med Ethics 2018;44:438-42.
13 Truog RD. The United Kingdom sets limits on experimental treatments: the case of Charlie Gard. JAMA 2017:318:1001-2.

14 Savulescu J. Is it in Charlie Gard's best interest to die? Lancet 2017;389:1868-9.

15 Wilkinson D, Savulescu J. After Charlie Gard: ethically ensuring access to innovative treatment. Lancet 2017:390:540-2.

16 McDougall RJ, Notini L. Overriding parents' medical decisions for their children: a systematic review of normative literature. J Med Ethics 2014;40:448-52.

17 Shah SK, Rosenberg AR, Diekema DS. Charlie Gard and the limits of best interests. JAMA Pediatr 2017;171:937-8.

18 Yates and Anor v Great Ormond Street Hospital and Anor [2017] EWCA Civ 410.

19 Willmott L, White B, Parker M, et al. Is there a role for law in medical practice when withholding and withdrawing life-sustaining medical treatment? Empirical findings on attitudes of doctors. J Law Med 2016;24:342-55.

20 Paris JJ, Ahluwalia J, Cummings BM, et al. The Charlie Gard case: British and American approaches to court resolution of disputes over medical decisions. J Perinatol 2017;37:1268-71.

21 Wilkinson D. Restoring balance to "best interests" disputes in children. BMJ 2017;358:j3666.

22 Downie J, Willmott L, White BP. Cutting the Gordian knot of futility: a case for law reform on unilateral withholding and withdrawal of potentially life-sustaining treatment. New Zealand Universities Law Rev 2014;26:24-59.

23 White B, Willmott L, Close E, et al. Withholding and withdrawing potentially life-sustaining treatment: Who should decide? In: Freckelton I, Petersen K eds. Tensions and Traumas in Health Law. Sydney, NSW: Federation Press, 2017:454-78

24 Pope TM. The best interest standard: both guide and limit to medical decision making on behalf of incapacitated patients. J Clin Ethics 2011;22:134-8.

25 Willmott L, White B, Smith MK. "Best interests" and withholding and withdrawing life-sustaining treatment from an adult who lacks capacity in the parens patriae jurisdiction. J Law Med 2014;21:920-41.

26 Pope TM. Texas Advance Directives Act: nearly a model dispute resolution mechanism for intractable medical futility conflicts. QUT Law Review 2016;16:22-53.

27 Truog RD. Counterpoint: the Texas Advance Directives Act is ethically flawed: medical futility disputes must be resolved by a fair process. Chest 2009;136:968-71.

28 Bosslet GT, Baker M, Pope TM. Reason-giving and medical futility: contrasting legal and social discourse in the United States with the United Kingdom and Ontario, Canada. Chest 2016;150:714-21.

29 White DB, Pope TM. The courts, futility, and the ends of medicine. JAMA 2012;307:151-2.

30 Carney T, Tait D. The Adult Guardianship Experiment: Tribunals \& Popular Justice. Leichhardt, NSW: Federation Press, 1997.

31 Re HG [2006] QGAAT 26. 5 May 2006.

32 Cuthbertson v Rasouli, 2013 SCC 53.

33 Hawryluck L, Baker AJ, Faith A, et al. The future of decision-making in critical care after Cuthbertson v. Rasouli. Can J Anaesth 2014;61:951-8. 